\title{
CITOLOGÍA CONVENCIONAL Y EN BASE LÍQUIDA EN MUESTRA COMPARTIDA DE TOMAS CERVICOUTERINAS
}

M iryam Puerto de A maya BSC, CITH*, Pablo M oreno-A costa, PhD**, M artha M ora M D***, Carlos Pérez M D****

\section{Resumen}

Objetivo: estandarizar la técnica de citología en base líquida mediante el uso del medio fijador (BDSUREPAth) y de citocentrífuga e identificar las posibles ventajas sobre citología convencional en muestra compartida de tomas cervicouterinas. Métodos: se incluyeron 92 muestras de mujeres que asistieron a las campañas del programa de proyección social de la Fundación Universitaria de Ciencias de la Salud, Bogotá DC, Colombia. Resultados: de las 92 muestras, 89 fueron negativas para citología convencional y 75 para base líquida, observándose un mayor número de casos con anormalidades en células escamosas en citología en base líquida. Conclusiones: las células escamosas mantienen su tonalidad citoplasmática siendo basófilas o acidófilas, conservando lo translúcido de los citoplasmas; las células glandulares preservan su patrón en panal de abejas o empalizada. Mediante citología en base liquida se obtienen fondos más limpios, las atipias de las células epiteliales fueron más fáciles de identificar al igual que los microorganismos patógenos. Palabras clave: citología, citología convencional, citología base líquida.

Abreviaturas: VPH, virus del papiloma humano; ASC-US, células escamosas atípicas de significado indeterminado.

\section{CONVENTIONAL AND LIQUID-BASED CYTOLOGY IN SHARED CERVICAL SAMPLES}

\begin{abstract}
Objective: to standardize the use of BD SurePath and centrifuged liquid-based cytology and identify possible advantages over the use of conventional cytology by comparing results on shared cervical samples analysis. Methods: we included 92 samples collected from women who attended the social projection campaign conducted by Fundación Universitaria de Ciencias de la Salud, Bogotá DC, Colombia. Results: out of the 92 samples, 89 were negative by conventional cytology and 75 by liquid-based cytology, evidencing a greater number of cases where squamous cell anomalies were detected using liquid-based cytology. Conclusions: squamous cells cytoplasma maintains its tone, being basophilic and acidophilic, conserving translucence; glandular cells preserve their honeycomb or palisade pattern. Liquid-based cytology gives a more clean background and improves identification of epithelial cell atypia as well as pathogenic microorganisms.
\end{abstract}

Key words: cytology, conventional cytology, liquid-based cytology

Fecha recibido: septiembre 30 de 2014 - Fecha aceptado:octubre 16 de 2014

* Profesora Asistente, Fundación Universitaria de Ciencias de la Salud, Bogotá DC, Colombia.

** PhD en Ciencias. Instituto Nacional de Cancerología. Bogotá DC, Colombia.

*** Médica Patóloga, Clínica Infantil Colsubsidio y Hospital La Victoria. Bogotá DC, Colombia.
**** Profesor Asociado, Fundación Universitaria de Ciencias de la Salud. Bogotá DC, Colombia.

Merideidy Plazas Vargas. Asesora metodológica. Profesora Asociada de Epidemiología, División de Investigaciones, Fundación Universitaria de Ciencias de la Salud, Bogotá DC, Colombia. 


\section{Introducción}

EI Dr. George Papanicolaou introdujo la técnica de citología cervicouterina como una ayuda diagnóstica y la American Cancer Society le concedió el aval por considerarla un apoyo eficaz para la prevención de lesiones premalignas y malignas del cuello uterino. ${ }^{1}$ Este método se mantuvo por varias décadas hasta los años 80, cuando el aporte científico y tecnológico modificó la citología convencional en busca de técnicas complementarias más sensibles y reproducibles como el análisis de ADN, la hibridación in situ y la modificación de la citología convencional por la de base líquida. Estos aportes ayudan a explicar el comportamiento biológico de la enfermedad y la posible asociación con virus del papiloma humano considerado como el agente causal más importante en la aparición de esta. ${ }^{2-5} \mathrm{~A}$ demás, la base líquida se usa para el estudio de citología no ginecológica, exfoliativa o por punción-aspiración en otras regiones anatómicas, permitiendo la posibilidad de elaborar bloques celulares a partir de la muestra residual. ${ }^{6-9}$ También, facilita el diagnóstico a distancia, la interconsulta de casos y el apoyo a docencia en el campo virtual por permitir imágenes libres de células inflamatorias y detritus biológicos. ${ }^{10,11}$

En citología convencional la no captura de la totalidad de la muestra se debe a que en los elementos de toma se desecha cerca del $80 \%$ de la muestra, deficiencia que en parte explica la generación de falsos negativos ${ }^{12,13}$; además de esta, la fijación incompleta por causa de extendidos gruesos da lugar a una coloración defectuosa.

De igual manera, la distribución no aleatoria de las células epiteliales imposibilita su análisis al quedar atrapadas por el moco u ocultas por la inflamación y la sangre, impidiendo la visualización de las células problema en deterioro de la calidad diagnóstica. ${ }^{14,15} \mathrm{~L}$ as investigaciones y los estudios realizados en países industrializados para mejorar la calidad en la toma, el proceso y la interpretación de la citología ginecológica, Ilevaron a la aprobación de algunas técnicas complementarias. Es así como en los Estados U nidos la FDA (The Food and D rug Administration) aprobó en mayo de 1966 la ThinP rep y en junio de 1999 la SurePath como métodos al ternativos para citología en esta modalidad. ${ }^{16}$ M ediante el uso de esta técnica, con una misma muestra se pueden realizar preparaciones para citología, prueba molecular para agentes infecciosos como V PH, análisis de A DN, inmunohistoquímica y bloque celular. En caso de un diagnóstico dudoso, facilita la reutilización de la muestra para citología. ${ }^{17,18}$

El objetivo de este trabajo fue estandarizar la técnica de citología en base líquida mediante el uso del medio fijador (BDSU REPAth) y de citocentrífuga e identificar las posibles ventajas sobre citología convencional en 92 extendidos cervicouterinos de mujeres que asistieron a las campañas del programa de proyección social de la Fundación U niversitaria de Ciencias de la Salud, Bogotá DC, Colombia.

\section{Materiales y métodos}

En el presente estudio se incluyeron mujeres mayores de 18 años con vida sexual activa y que aceptaron firmar el respectivo consentimiento informado. Se recolectan 92 muestras cervicouterinas de mujeres que asistieron a las campañas en L a M esa (Cundinamarca), Hospital de San José y Centro Social, del programa de proyección social de la Facultad de Citohistología de la Fundación U niversitaria de Ciencias de la Salud (FUCS). U na vez diligenciado el formato de recolección de datos de acuerdo con la reglamentación, ${ }^{19-30}$ se hizo primero la toma de la citología convencional y el material residual almacenado en los elementos usados se guardó en un vial que contenía la solución comercial.

Para estandarizar esta técnica manual de citología en base líquida utilizando el material residual, fue necesaria para la preservación de las muestras una solución fijadora BD SurePath (liquid-based Pap test) de la casa comercial Becton Dickinson (vial con etanol) y para obtener el botón de la muestra se recurrió a una citocentrífuga (Cytospin 4 Thermo Scientific $\AA$ ) como método al terno al que ofrecen las casas comerciales, y por úl timo el material fue fijado de inmediato y quedó extendido en un área de $6 \mathrm{~mm}$ de diámetro. 


\section{Material para citología convencional}

EI material epitelial del exo y endocervix se extendió sobre un portaobjeto de vidrio rotulado con los datos de identificación de la paciente y de inmediato se fijó con una solución comercial para tal fin (Cytospray) a una distancia de unos $30 \mathrm{~cm}$ de la muestra para no estallar las células e impedir la desecación del material biológico. Éstas preparaciones acompañadas de su correspondiente formato de recolección diligenciado con los datos de historia de la paciente, fue llevado al laboratorio para el estudio de citología convencional.

\section{Material para citología en base líquida}

L a muestra para la citología en base líquida se guardó en un vial identificado con los datos de la paciente, junto con la espátula de Ayre y el citocepillo utilizados en las tomas de la citología convencional (muestra residual compartida, no directo al vial). Los viales se almacenaron por un lapso aproximado de cuatro meses a $4^{\circ} \mathrm{C}$. Después las muestras fueron procesadas en una citocentrífuga de acuerdo con las recomendaciones de la casa comercial.

Para definir la cantidad de muestra se realizaron pruebas con 100 uL y 200 uL; con la primera los extendidos fueron escasos en células epiteliales y con 200 uL la interpretación en al gunas muestras no fue adecuada por la superposición celular. En otras muestras el botón de la preparación se desprendió en el transcurso de la coloración quedando escaso material, siendo acelular la preparación. L a cantidad de muestra empleada para cada caso fue de $150 \mathrm{uL}$, volumen que se depositó en una cámara (C ytofunnel) y luego se centrifugó a 1.000 rpm por 5 minutos. El proceso de centrifugación por la técnica de transferencia de células de una suspensión a una superficie, permite separar las células del componente líquido transportándolas en forma directa al portaobjeto por la fuerza centrífuga, para que puedan quedar aplanadas y adheridas en un área de más o menos $6 \mathrm{~mm}$ para ser fijadas y coloreadas. La parte líquida de esta solución que acompaña la muestra se absorbe y se retiene dentro del filtro., 31,32

\section{Coloración-tinción}

Las preparaciones tanto de la citología convencional como de base líquida fueron teñidas con la coloración de Papanicolaou y su análisis se hizo de acuerdo con la clasificación Bethesda. Las de base líquida se examinaron bajo los parámetros de bueno, regular y malo, teniendo en cuenta los pasos de la técnica como fijación, coloración y fondo de la preparación. La morfología celular fue analizada en cuanto al núcleo, citoplasma y relación entre estos dos. También fue importante evaluar la calidad de la muestra de acuerdo con los parámetros establecidos por la clasificación B ethesda: 1) satisfactoria con células endocervicales o zona de transformación; 2) satisfactoria sin células endocervicales o zona de transformación; 3) insatisfactoria procesada y examinada y 4) rechazada 0 no procesada. En la categorización general, para la interpretación del resultado: 1) negativo para lesión intraepitelial o malignidad; 2) anormalidades de céIulas epiteliales (escamosas y glandulares) y 3) flora patógena (Figura 1).

\section{Interpretación}

L as muestras de las citologías convencionales fueron analizadas por una citohistóloga con más de diez años de experiencia. Los casos con A SC-US, con lesión escamosa intraepitelial de bajo grado y el control interno del $10 \%$ para las citologías negativas, fueron revisados por un patólogo. L os análisis realizados a las citologías en base líquida también fueron hechos por otra citohistóloga con similares años de experiencia en un ejercicio doble ciego. Los casos clasificados como A SC-US con lesiones escamosas intraepiteliales y el control interno del $10 \%$ para casos negativos, Ios analizó un segundo patólogo.

\section{Resultados}

La evaluación de la calidad de la muestra en extendidos convencionales y citología líquida por medio del sistema B ethesda mostró mejor calidad en los primeros 
(Tabla 1). A I comparar la calidad de las 92 muestras que equival en a $100 \%$, seis fueron insatisfactorias para la técnica base líquida frente a $0 \%$ de la convencional (Tabla 2). Del total (92) por la técnica de base líquida fueron catal ogadas seis A SC-US y dos lesi ones escamosas intraepiteliales de bajo grado más que por la citología convencional (Tabla 3). La comparación de la distribución de acuerdo con la clasificación B ethesda en cada técnica con el total de 92 muestras se analiza en la Tabla 4.

\section{Disc usión}

En esta primera experiencia de trabajar con la modificación de la técnica de citología (en base liquida), en muestra compartida no directo al vial, se observó una mejor calidad de la muestra en cuanto a coloración uniforme y preservación morfológica. Caso diferente al hablar de calidad de la muestra en cuanto a representación celular; donde el material del canal endocervical estuvo pobremente representado por células endocervicales o células metaplásicas (zona de transformación). Esta diferencia se explica por la imposibilidad al no guardar el $100 \%$ de la toma cervicouterina (directo al vial). En este estudio se tuvo en cuenta la reco- mendación de Bethesda: "mínimo aproximado de al menos 5.000 células escamosas bien conservadas que se reconocen adecuadamente," para aceptar el caso como satisfactorio. También, la realización de la toma de la muestra en cada caso determina un factor muy importante en los hallazgos, lo que plantea la necesidad y la importancia de la estandarización de una técnica.

La importancia de la representación epitelial de esta región anatómica en los extendidos vaginales radica en el tropismo del V PH por las células metaplásicas e inmaduras y los posibles cambios morfológicos que se producen y son clasificados por Bethesda como: "anormalidades de células epiteliales". En el análisis de las muestras por base líquida, se registraron más casos como A SC-US y lesión de bajo grado. Esta diferencia en los hallazgos de los resultados con respecto a la convencional, es motivo de discusión en la literatura, ya que en al gunos estudios las atipias en base líquida van en aumento y en otros se reporta su disminución.

El análisis y la interpretación de la citología en base líquida mediante el uso de la técnica de citocentrifugación, crea la necesidad de un adiestramiento visual para
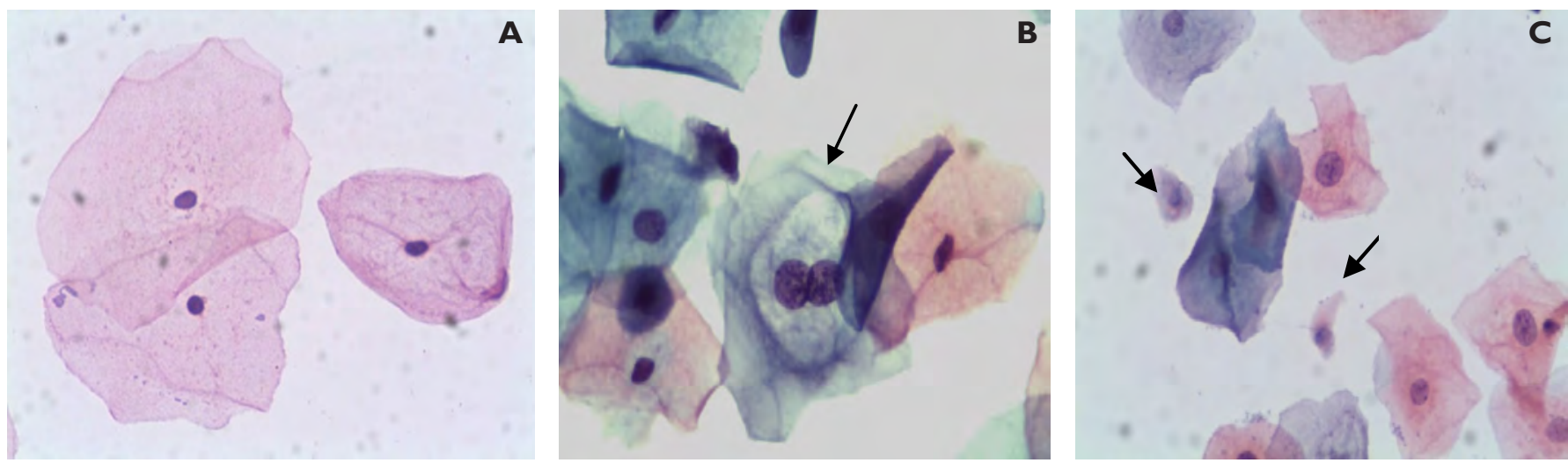

Figuras I. A, B y C. Imágenes tomadas de las preparaciones por base líquida. A) Células escamosas de tipo superficial, B) coilocitos y C) flora patógena (tricomonas).

Tabla I. Evaluación de la calidad de la muestra (Bethesda)

\begin{tabular}{|l|c|c|c|}
\hline Interpretación $\mathbf{n}(\%)$ & C.C.* & B.L. $†$ & Total muestras \\
\hline Satisfactoria con glandulares & $77(83.7)$ & $59(64.13)$ & 92 \\
\hline Satisfactoria sin glandulares & $15(16.3)$ & $27(29.35)$ & 92 \\
\hline Insatisfactoria & 0 & $6(6.52)$ & 92 \\
\hline
\end{tabular}

* Citología convencional; $†$ citología en base líquida. 


\begin{tabular}{|c|c|c|c|c|}
\hline \multirow{2}{*}{\multicolumn{2}{|c|}{ Observador citología base líquida n(\%) }} & \multicolumn{3}{|c|}{ Observador citología convencional } \\
\hline & & $\begin{array}{c}\text { Insatisfactoria } \\
\mathbf{n}(\%)\end{array}$ & $\begin{array}{l}\text { Satisfactoria sin células } \\
\text { endocervicales ni zona } \\
\text { de transformación n (\%) }\end{array}$ & $\begin{array}{l}\text { Satisfactoria con células } \\
\text { endocervicales y zona } \\
\text { de transformación n(\%) }\end{array}$ \\
\hline Insatisfactoria & $6(6,52)$ & 0 & $2(14,2)$ & $4(5,1)$ \\
\hline $\begin{array}{l}\text { Satisfactoria sin células } \\
\text { endocervicales y zona de } \\
\text { transformación }\end{array}$ & $27(29,35)$ & 0 & II $(78,6)$ & $16(20,5)$ \\
\hline $\begin{array}{l}\text { Satisfactoria con células } \\
\text { endocervicales y zona de } \\
\text { transformación. }\end{array}$ & $59(64,13)$ & 0 & $I(7, I)$ & $58(74,4)$ \\
\hline Total & $92(100)$ & 0 & $14(100)$ & $78(100)$ \\
\hline
\end{tabular}

\begin{tabular}{|l|c|c|c|}
\hline \multicolumn{4}{|c|}{ Tabla 3. Clasificación con base líquida } \\
\hline $\begin{array}{c}\text { Interpretación } \\
\text { n(\%) }\end{array}$ & C.C.* & B.L. $\dagger$ & $\begin{array}{c}\text { Total } \\
\text { muestras }\end{array}$ \\
\hline Negativa & $89(96,74)$ & $75(81,52)$ & 92 \\
\hline ASC-US $\ddagger$ & $2(2,17)$ & $8(8,70)$ & 92 \\
\hline LEIBG $\S$ & $1(1,09)$ & $3(3,26)$ & 92 \\
\hline Insatisfactoria & 0 & $6(6,52)$ & 92 \\
\hline
\end{tabular}

* Citología convencional; † Citología base líquida; $¥$ Células escamosas atípicas de significado indeterminado; § lesión escamosa intraepitelial de bajo grado.

\begin{tabular}{|c|c|c|c|c|}
\hline \multirow{2}{*}{\multicolumn{2}{|c|}{$\begin{array}{l}\text { Observador citología } \\
\text { base líquida } n(\%)\end{array}$}} & \multicolumn{3}{|c|}{$\begin{array}{l}\text { Observador citología } \\
\text { convencional } n(\%)\end{array}$} \\
\hline & & $\begin{array}{c}\text { Negativa } \\
\text { n(\%) }\end{array}$ & $\begin{array}{c}\text { ASC-US* } \\
\text { n(\%) }\end{array}$ & $\begin{array}{c}\text { LEIBG } \uparrow \\
n(\%)\end{array}$ \\
\hline Negativa & $75(8 I, 5)$ & $75(84,3)$ & 0 & 0 \\
\hline ASC-US* & $8(8,7)$ & $6(6,7)$ & $2(100)$ & 0 \\
\hline LEIBG $\dagger$ & $3(3,3)$ & $2(2,2)$ & 0 & $I(100)$ \\
\hline Insatisfactoria & $6(6,5)$ & $6(6,7)$ & 0 & 0 \\
\hline Total & $92(100)$ & $89(100)$ & $2(100)$ & $I(100)$ \\
\hline
\end{tabular}

*Células escamosas atípicas de significado indeterminado; † Lesión escamosa intraepitelial de bajo grado.

poder interpretar un ligero aumento del tamaño celular sin alteración de la relación núcleo y citoplasma, que se explica por la fuerza centrifuga utilizada para el transporte de las células y la adhesión al portaobjeto. El entrenamiento visual es importante porque esta técnica permite una mejor definición del componente morfológico como detalle más claro de la cromatina, así como cromocentros y nucléolos más visibles, características que no son tan prominentes en la citología convencional. Las tonalidades de los citoplasmas de acuerdo con el grado de maduración, se mantuvieron tomando una basófila (azul) o acidófila (rosada) y las células intermedias y superficial es conservaron lo translúcido y brillante del gran citoplasma que poseen. L as células glandulares endocervical es se observaron con la forma usual de "panal de abejas", en empalizada 0 aisladas, similares a las de las muestras convencionales. L lamó la atención las mejoras obtenidas en los fondos de los extendidos que estuvieron libres de sangre y moco, solo se observaron células inflamatorias, hallazgo normal ya que la técnica utilizada no tenía como objetivo eliminarlas. Las atipias de las células epiteliales en base líquida fueron más fáciles de identificar al carecer de elementos que las ocultaran como el moco y la sangre; las irregularidades de los núcleos son fáciles de observar, de igual forma que el contorno nuclear irregular, así también los halos perinucleares (Figura 1B) y la atipia de las células escamosas, que muestran una ligera alteración de la relación núcleo y citoplasma debido al agrandamiento del núcleo (dos veces y media más que el tamaño de una célula intermedia), clasificación según B ethesda. ${ }^{6}$

Dentro de la flora patógena hallada en éstas muestras se observaron Actinomyces (sp) y flora bacteriana sugestiva de vaginosis, microorganismos que también estuvieron presentes en los extendidos convencional es. L a Trichomona vaginalis (Figura 1C) solo se registró en la citología en base líquida utilizando los criterios morfológicos asociados con esta infección. ${ }^{33,34}$ 
En la actualidad la adquisición por parte de la Facultad de Citohistología del equipo manual para la técnica de base líquida de la casa comercial Becton Dickinson, nos permite enriquecer nuestra experiencia en el campo de la investigación, proponiendo nuevos temas tanto en citología vaginal como no ginecológica, y la aplicación de otras técnicas como la prueba de detección del HPV. ${ }^{35,36}$

Haciendo una revisión acerca del tema se encuentra una publicación del M inisterio de Salud y Protección Social y del Instituto Nacional de Cancerología Empresa Social del Estado en su "PLAN NACIONAL PARA EL CONTROL DEL CÁNCER EN COLOMBIA 2012-2020". Se plantea una propuesta para 2013 sobre la transición de la tamización de cáncer de cuello uterino, de citología a pruebas moleculares de detección temprana de V PH en las cinco principales ciudades del país (B ogotá, M edellín, Cali, Barranquilla y Bucaramanga)". Con ello se ratifica la necesidad de reemplazar la citología convencional por la de base líquida y el uso de pruebas complementarias más sensibles y reproducibles, donde la citología no estaría como prueba primaría para tamizaje, sino como ayuda en los casos de control para mujeres con diagnósticos de ASC-US y anomalías de células epiteliales, que sería un trabajo en conjunto de aplicación de estas técnicas. El cambio obliga a los profesionales a ampliar su conocimiento en la aplicación de nuevas tecnologías y en el manejo de los resultados.

\section{Referencias}

1. Albujar P. Reseña histórica de la citología diagnostica. Ginecol. Obstetr [serie en Internet]. 2001 [citado 20 Feb 2015]; 47(2): [aprox. 3 p.]. Disponible en: http:// sisbib.unmsm.edu.pe/bvrevistas/ginecologia/vol_47n2/resena_histo.htm

2. Cancers of the female reproductive tract. In: Stewart B, Kleihues P, editors. World Cancer Report. Lyon: WHO, IARC; 2003. p. 215-22.

3. Conference on the State of the Art in Quality Control Measures for Diagnostic Cytology Laboratories. Atlanta, Georgia, March 1-2, 1988. Proceedings. Acta Cytol 1989 Jul; 33(4):423-90.

4. Wei Q, Liu J, Zhang Z, Yang Q, Zhao T. Morphological features of cell blocks prepared from residual liqui-PREP samples can distinguish between high-grade squamous intraepithelial lesions and squamous cell carcinomas. Acta Cytol. 2011; 55(3): 245-50.

5. Sáez de Santamaría J, Rodríguez Costa J, de Agustín Vásquez, A. Citología Líquida. Madrid: Díaz de Santos; 2006

6. Shah P, Deshmukh R. Exfoliative cytology and cytocentrifuge preparation of ora premalignant and malignant lesions. Acta Cytol. 2012; 56(1):68-73.

7. Fadda G, Rossi ED. Liquid-based cytology in fine-needle aspiration biopsies of the thyroid gland. Acta Cytol. 2011; 55(5):389-400.

8. Yoshida T, Sano T, Kanuma T, Inoue H, Itoh T, Yazaki C, et al. Usefulness of CINtec(R) PLUS p16/Ki-67 double-staining in cytological screening of cervical cancer. Acta Cytol. 2011; 55(5):413-20.

9. Lee JK, Choi ER, Jang TH, Chung YH, Jang KT, Park SM, et al. A prospective comparison of liquid-based cytology and traditional smear cytology in pan- creatic endoscopic ultrasound-guided fine needle aspiration. Acta Cytol. 2011; 55(5):401-7.

10. Kaminsky DB. Transforming cytology. Acta Cytol. 2011; 55(3):225-6.

11. Wilbur DC. Digital cytology: current state of the art and prospects for the future. Acta Cytol. 2011;55(3):227-38.

12. Soost HJ, Lange HJ, Lehmacher W, Ruffing-Kullmann B. The validation of cervical cytology. Sensitivity, specificity and predictive values. Acta Cytol. 1991 Jan; 35(1):8-14.

13. Hutchinson ML, Isenstein LM, Goodman A, Hurley AA, Douglass KL, Mui KK, et al. Homogeneous sampling accounts for the increased diagnostic accuracy using the ThinPrep Processor. Am J Clin Pathol. 1994 Feb; 101(2):215-9.

14. Koss LG. Utility of liquid-based cytology for cervical carcinoma screening. Cancer. 2000 Feb 25; 90(1):67-9.

15. Takahashi M, Naito M. Application of the CytoRich monolayer preparation system for cervical cytology. A prelude to automated primary screening. Acta Cytol. 1997 Nov; 41(6):1785-9.

16. Gutman S. Labeling liquid-based systems: FDA clarification. Acta Cytol. 2000 Nov; 44(6):1120

17. Taoka H, Yamamoto Y, Sakurai N, Fukuda M, Asakawa Y, Kurasaki A, et al. Comparison of conventional and liquid-based cytology, and human papillomavirus testing using SurePath preparation in Japan. Hum Cell. 2010 Nov; 23(4):126-33.

18. Rodríguez P, Puerto M. Comparación entre las técnicas de citología compartida: convencional vs. base líquida. Repert Med Cir. 2011; 20(4): 240-4.

19. Colombia. Ministerio de Salud. Resolución número 5810 de 1976 (Julio 26) por la cual se regula la actividad de los citotecnólogos

20. Colombia. Congreso. Ley 9 de 1979 por la cual se dictan Medidas Sanitarias

21. Colombia. Congreso. Ley 100 de 1993 (Diciembre 23) por la cual se crea el sistema de seguridad social integral y se dictan otras disposiciones

22. Colombia. Consejo Nacional de Seguridad Social en Salud. Acuerdo 117 de 1998 (Diciembre 29) por el cual se establece el obligatorio cumplimiento de las actividades, procedimientos e intervenciones de demanda inducida y la atención de enfermedades de interés en salud pública.

23. Colombia. Ministerio de Salud. Resolucion 4547 de 1998 Por la cual se definen los exámenes de laboratorio en alimentos, bebidas, medicamentos, cosméticos, insumos para la salud y productos varios de interés en salud pública, que deben realizar los laboratorios de salud pública departamentales y distritales, los laboratorios clínicos y los laboratorios de citohistopatología.

24. Colombia. Congreso. Ley 872 de 2003 por la cual se crea el sistema de gestión de la calidad en la Rama Ejecutiva del Poder Público y en otras entidades prestadoras de servicios.

25. Colombia. Ministerio de Salud. Decreto 2309 de 2002 (Octubre 15) por el cual se define el Sistema Obligatorio de Garantía de Calidad de la Atención de Salud del Sistema de Seguridad Social en Salud

26. Colombia. Ministerio de la Protección Social. Decreto 1011 de 2006 (Abril 3) por el cual se establece el Sistema Obligatorio de Garantía de Calidad de la Atención de Salud del Sistema General de Seguridad Social en Salud

27. Colombia. Ministerio de la Protección Social. Resolución 1043 de 2006 (Abril 3) por la cual se establecen las condiciones que deben cumplir los Prestadores de Servicios de Salud para habilitar sus servicios e implementar el componente de auditoría para el mejoramiento de la calidad de la atención y se dictan otras disposiciones.

28. Colombia. Ministerio de la Protección Social. Ley 2680 de 2007 por la cual se modifica parcialmente la Resolución 1043 de 2006 y se dictan otras disposiciones

29. Colombia. Ministerio de la Protección Social. Decreto 2323 de 2006 (Julio 12) por el cual se reglamenta parcialmente la ley 09 de 1979 en relación con la Red Nacional de Laboratorios y se dictan otras disposiciones

30. Colombia. Ministerio de Salud. Resolución 412 de 2000 por la cual se establecen las actividades, procedimientos e intervenciones de demanda inducida y obligatorio cumplimiento y se adoptan las normas técnicas y guías de atención para el desarrollo de las acciones de protección específica y detección temprana y la atención de enfermedades de interés en salud pública

31. Gill GW. The Shandon Cytospin 2 in diagnostic cytology. In: Cytospin2 Handbook. Sewickley,PA: Shandon Southern Instruments; 1982. p. 11-52.

32. Thermo Electron Corporation. Shandon Cytospin 4 Manual de operaciones. 4a ed Pittsburgh: The Corporation; 2004.

33. Noel JC, Engohan-Aloghe C. Morphologic criteria associated with Trichomonas vaginalis in liquid-based cytology. Acta Cytol. 2010 Jul; 54(4):582-6.

34. Castle PE, Hildesheim A, Schiffman M, Gaydos CA, Cullen A, Herrero R, et al. Stability of archived liquid-based cytologic specimens. Cancer. 2003 Oct 25; 99(5):320-2

35. Hayama FH, Motta AC, Silva AP, Migliari DA. Liquid-based preparations versus conventional cytology: specimen adequacy and diagnostic agreement in oral lesions. Med Oral Patol Oral Cir Bucal. 2005 Mar; 10(2):115-22.

36. Wen CH, Tsao SC, Su YC, Wu CC, Chai CY. Utility of the capsule-based technique for cell block preparation-in body fluids and Liqui-PREP specimens. Acta Cytol. 2011; 55(5):460-6. 